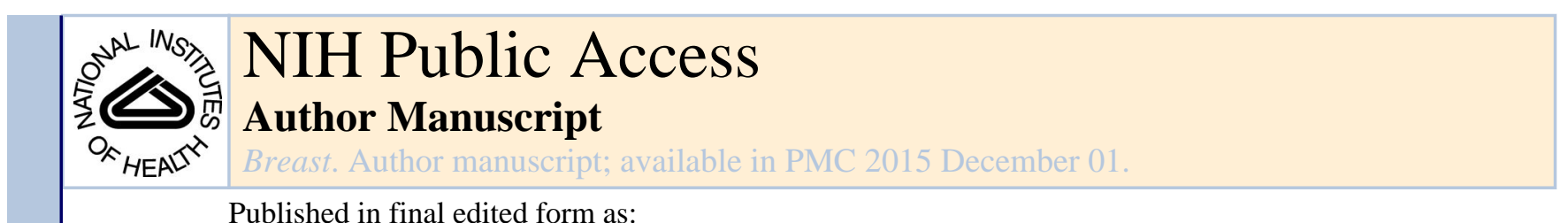

Published in final edited form as:

Breast. 2014 December ; 23(6): 743-748. doi:10.1016/j.breast.2014.08.002.

\title{
Online Support: Impact on Anxiety in Women Who Experience an Abnormal Screening Mammogram
}

\author{
Eniola T. Obadina, MD ${ }^{1}$, Lori L. Dubenske, $\mathrm{PhD}^{2}$, Helene E. McDowell, MS ${ }^{2}$, Amy K. \\ Atwood, PhD ${ }^{2}$, Deborah K. Mayer, PhD, RN, AOCN, FAAN ${ }^{3}$, Ryan W. Woods, MD, MPH ${ }^{4}$, \\ David H. Gustafson, PhD $^{2}$, and Elizabeth S. Burnside, MD, MPH, MS ${ }^{4}$ \\ ${ }^{1}$ Department of Radiology, Johns Hopkins University, Baltimore, MD \\ ${ }^{2}$ Center for Health Enhancement System Studies (CHESS), University of North Carolina, Chapel \\ Hill, NC \\ ${ }^{3}$ School of Nursing, University of North Carolina, Chapel Hill, NC \\ ${ }^{4}$ Department of Radiology, University of Wisconsin, Madison, WI
}

\begin{abstract}
OBJECTIVES-To determine whether an online support tool can impact anxiety in women experiencing an abnormal mammogram.
\end{abstract}

\begin{abstract}
MATERIALS AND METHODS-We developed an online support system using the Comprehensive Health Enhancement Support System (CHESS) designed for women experiencing an abnormal mammogram as a model. Our trial randomized 130 of these women to online support (the intervention group) or to a list of five commonly used Internet sites (the comparison group). Surveys assessed anxiety and breast cancer worry, and patient satisfaction at three important clinical time points: when women were notified of their abnormal mammogram, at the time of diagnostic imaging, and at the time of biopsy (if biopsy was recommended).
\end{abstract}

RESULTS-Study participants in the intervention group showed a significant decrease in anxiety at the time of biopsy compared to the comparison group $(\mathrm{p}=0.017)$. However, there was no significant difference in anxiety between the intervention group and the comparison group at the time of diagnostic work-up. We discontinued assessment of patient satisfaction after finding that many women had substantial difficulty answering the questions that referenced their physician, because they did not understand who their physician was for this process of care.

\footnotetext{
(C) 2014 Elsevier Ltd. All rights reserved.

Corresponding Author: Dr. Elizabeth Burnside (EBurnside@uwhealth.org), Department of Radiology, University of Wisconsin, 600 Highland Ave, E3/366 Clinical Science Center, Madison, WI 53792-3252.

Publisher's Disclaimer: This is a PDF file of an unedited manuscript that has been accepted for publication. As a service to our customers we are providing this early version of the manuscript. The manuscript will undergo copyediting, typesetting, and review of the resulting proof before it is published in its final citable form. Please note that during the production process errors may be discovered which could affect the content, and all legal disclaimers that apply to the journal pertain.

Conflict of interest statement

None of the authors have any conflict of interest.

Ethical approval statement

Informed consent was obtained for experimentation with human subjects prior to the study.
} 
CONCLUSION-The combination of the inability to identify the physician providing care during the mammography work-up and anxiety effects seen only after an interaction with the breast imaging team may indicate that online support only decreases the anxiety of women in concert with direct interpersonal support from the healthcare team.

\section{Introduction}

Screening mammography reduces breast cancer mortality through earlier detection of smaller, more curable cancers (1). Of all screening mammograms, approximately $10 \%$ will be found to be abnormal and require additional evaluation, but only $0.1 \%$ to $0.5 \%$ of women who undergo screening mammography will actually be diagnosed with breast cancer (2). This means that despite a highly specific screening test (>90\%), the vast majority of abnormal exams are false positives. False positive examinations lead to additional studies, such as diagnostic mammograms and ultrasound, and even biopsy procedures (3). This can result in anxiety, which could have a negative impact on future screening behaviors (3-6). Therefore, an intervention that decreases anxiety would be useful.

The impact of an abnormal mammogram on women's psychological well-being is an active area of research $(3,4,6-10)$. Some women develop considerable psychological distress, particularly anxiety (3), at the time of abnormal mammography (11-14). For example, 16\% of women felt certain they had breast cancer (15), and about $30 \%$ felt "very anxious" after receiving the letter notifying them of an abnormal result (the "recall letter") (15). Prolonged waiting periods between the time of the screening mammogram and the diagnostic mammogram can also increase anxiety $(16,17)$. The literature reflects variable findings regarding how long anxiety continues after false positive mammography, with some studies reporting a range from several months to as long as 3 years (13-15, 17-23). During the diagnostic workup, women rely on social support networks (24) and educate themselves about breast cancer to manage their anxiety and prepare for a diagnosis (25-27), suggesting that tailored information in the form of an online support module may help women during this period, when few quality resources are available and many questions remain unanswered. Interaction with a healthcare provider $(17,28)$, but not basic informational materials (29), is effective at reducing anxiety.

The Internet has become a primary source for health information and emotional support for patients (30); however, the information provided is often of poor quality (31-32) and patients frequently remain without information until interacting with healthcare staff. The Comprehensive Health Enhancement Support System (CHESS) has been shown to improve women's ability to seek out information and obtain support after a breast cancer diagnosis (33). CHESS is a computer-and web-based tool that incorporates searchable health information, an interactive component that guides patients by making suggestions and giving feedback, and a module that links them electronically with other patients with breast cancer. For this project, we implemented an online support module (Early CHESS), which modifies the health information features of CHESS to focus on women with abnormal screening mammogram results. 
The purpose of this pilot study was to evaluate the impact of Early CHESS on women with an abnormal screening mammogram by assessing anxiety, breast cancer worry, and patient satisfaction with the radiologist.

\section{Materials and Methods}

\section{Clinical process}

The study procedure was integrated into the standard clinical process at the University of Wisconsin (UW) Breast Center (see Figure 1). After a screening mammogram is performed on an asymptomatic woman, the images are evaluated by a radiologist. A decision is then made to either return the patient to routine screening or recall the patient for additional imaging. If diagnostic mammography is indicated to work-up an abnormality, the patient receives a phone call from a nurse, is sent a recall letter, and the primary care physician is notified. At the follow-up appointment, a diagnostic mammogram is performed, providing the first opportunity for the patient to interact in person with clinical staff since the receipt of the recall letter (Figure 1). After the radiologist evaluates the diagnostic mammogram, a decision is then made to return the patient to routine screening, recommend a six-month follow-up, or recommend a biopsy. A biopsy is recommended when the findings on mammography are concerning and tissue sampling is warranted for further evaluation. At the UW Breast Center, patients always meet with a radiologist if a diagnostic ultrasound is performed or if a biopsy is recommended.

\section{Power and Sample Size}

Based on our previous experience with online support for breast cancer, we estimated a 10\% drop out rate over the study period. We also anticipated that some assessments would be missing for other reasons. Given an anticipated moderately small treatment effect size of .4 s.d. with a power of $80 \%$, a one-tailed alpha of .05 , and baseline-outcome measure correlations of .60, we concluded that we would need a completed sample size of 102 . We thus decided to recruit a total sample of 130 , in order to accommodate for attrition or missing data.

\section{Recruitment}

After Institutional Review Board (IRB) approval was obtained, recruitment was conducted from June 2010 to November 2011. Inclusion criteria included: women who were >21 years old, able to read and understand English, had access to the Internet, and were being recalled for diagnostic imaging after a screening mammography. The women were invited to participate by nurses who notified them of their abnormal mammogram, which occurred prior to the receipt of the recall letter notifying them of their abnormal results. After permission was obtained, a research staff called each woman, explained the details of the study, answered questions, obtained verbal consent, collected contact information and demographic data, and the baseline survey questionnaire was completed. At the time of enrollment, the research staff confirmed the participant's recall appointment time and met the patient at the UW Breast Center to complete the second survey and obtain written consent. 


\section{Intervention}

Once the research staff completed verbal consent and the baseline telephone survey, participants were randomized via a computer-generated list that was accessed by the study director. Each participant was informed of her randomization group. The comparison group received a list of five credible breast imaging websites (see Appendix 1) via email. Subjects randomized to the intervention (Early CHESS) group received an email with instructions for accessing the Early CHESS website, including login information.

\section{The Online Support Module}

Early CHESS was developed by the UW's Center for Health Enhancement Systems Studies and includes breast health, imaging and expert content in a variety of formats, including Q\&As, web links and articles. Early CHESS also has content on breast cancer diagnosis and treatment.

\section{Survey Instruments}

The impact of Early CHESS was evaluated in two domains: (1) anxiety and breast cancer worry and (2) patient satisfaction with their physician interaction during three time points by the research coordinator (Figure 1). The baseline survey was completed by phone at enrollment. The second assessment was conducted at the time of the diagnostic appointment, immediately prior to diagnostic breast imaging (usually within 2-3 days of the notification letter), and the third assessment (for the women needing biopsy) was completed after meeting with the breast imaging team (nurse and radiologist) and immediately before the biopsy procedure (usually within 1 week of the notification letter).

Anxiety and Breast Cancer Worry-Previously validated psychometric questionnaires were used to assess women' anxiety and breast cancer worry.

- State anxiety was measured using the State Anxiety (SA) subscale of the StateTrait Anxiety Inventory (STAI) (34) at all three time points. Items were rated on a 0 to 3 Likert-type scale with scores calculated as item sums with a possible range of 0 to 60 , higher scores indicating greater state anxiety. For our sample, cronbach's alpha was 0.94 at initial baseline administration $(n=126)$.

- The Breast Cancer Worry subscale of the Lerman Breast Cancer Worry Scale (LBCWS) (35), designed specifically to assess the constructs of breast cancer worry, was also administered at all three time points. This single item, "How worried are you about getting breast cancer someday?" was rated on a 0 ("Not at all") to 4 ("Almost all the time") Likert scale.

Patient satisfaction-The Patient Satisfaction with Doctor Questionnaire (PSQ-MD) (37) was administered at all three time points. This scale has two subscales: Physician Disengagement and Perceived Support, with items rated on a 0 to 3 Likert scale and scores calculated as item sums with a possible range of 0 to 72 . Cronbach's alpha was $0.89(n=20)$ and $0.86(n=15)$, respectively, at baseline. 
Demographic variables-Data on potentially confounding variables, such as age, education, personal health history, family history of breast cancer, and previous abnormal screening mammography, were collected at the time of consent. The time course of notification, enrollment and follow-up appointments was also recorded.

\section{Statistical Analysis}

The STAI and LBCWS measures were obtained for each of the three time points: at baseline (Pre), at diagnostic mammogram (Dx) and at biopsy (Bx). Change scores across time points, expressed as a percentage, were obtained and summarized with quartiles (see Appendix 2). Differences between the intervention (Early CHESS) and comparison groups for each change measure were assessed with Kruskal-Wallis tests. $\mathrm{P}<0.05$ (two-sided) was used as the criterion for statistical significance. There was no adjustment for multiple comparisons. Statistical analyses and graphics were performed using R statistical software (version 2.12.1; R Development Core Team) (38).

\section{Results}

\section{Population characteristics and demographics}

179 women were initially approached for study participation (Figure 2), with 130 women ultimately being enrolled in the study and randomized to one of two groups, the Early CHESS group or the comparison group. Seven (7) women dropped out of the study after enrollment (two were from the comparison group and five were from the Early CHESS group) for one of several reasons: felt too overwhelmed to participate, no longer interested, had diagnostic evaluation at a different facility, or had a breast MRI rather than biopsy. One of these seven women dropped out after giving consent, but before the baseline survey and demographic data were obtained. Therefore, baseline survey and demographic data were collected on 129 women (65 in the comparison group and 64 in the Early CHESS group).

Each study participant was asked to indicate the age range that describes her current age, with the majority of the participants being within the American College of Radiology (ACR) recommended mammography screening age range. The overall age distribution was similar for both the comparison and the Early CHESS groups.

Majority (98\%) of the study participants were Caucasian. The study population overall was well educated, with $67 \%$ of the comparison group and 69\% of the Early CHESS group reporting having a four-year college degree or higher. Thirty-five women in the comparison group had a family history of breast cancer, compared to twenty-four women in the Early CHESS group. The majority of the participants in this study (86\%) noted a personal history of abnormal mammogram and/or biopsy (Figure 3).

Twenty-three women (35.4\%) in the comparison group went on to have a biopsy, compared to $20(31.3 \%)$ of the women in the Early CHESS group. The average amount of time between the time of the baseline survey and the diagnostic appointment was 3.5 days for the comparison group, and 5.1 days for the Early CHESS group; while the mean number of days between the diagnostic appointment and the time of biopsy was 14 days for the comparison group, and 9.6 days for the Early CHESS group. 


\section{Impact on patient anxiety}

At baseline, the State Anxiety (SA) scores had a mean of 21.35 ( $\mathrm{SD}=13.43)$ for the comparison group, and a mean of 17.12 ( $\mathrm{SD}=10.55)$ for the Early CHESS group. There was a significant difference in the change scores (see Appendix 2) for SA between the comparison group and the Early CHESS group at biopsy ( $\mathrm{p}=0.02$ ), but not at the time of diagnostic work-up $(\mathrm{p}=0.24)$. The median percent change score for SA for the comparison group at the time of diagnostic work-up was $-11.03(-44.29,+16.01$; i.e. first quartile, third quartile), while the corresponding score for the Early CHESS group was $-22.73(-43.95$, +7.28), $\mathrm{p}=0.24$ (see Figure 4 for box and whisker plots).

The median percent change score for SA for the comparison group at biopsy was 0.00 $(-22.71,+30.09)$, compared to the Early CHESS group of $-40.91(-128.10,-15.00), \mathrm{p}=$ 0.02 (Figure 5).

\section{Impact on patient breast cancer worry}

There was no significant difference in the percent change scores for the Breast Cancer Worry subscale between the comparison group and the Early CHESS group, either at diagnostic work-up $(\mathrm{p}=0.60)$ or at the time of biopsy $(\mathrm{p}=0.72)$.

\section{Impact on patient satisfaction}

Patient satisfaction was not included in the data analysis because many of the study participants had difficulty answering questions pertaining to satisfaction with their physician interaction. Patients expressed uncertainty about which physician was directing this process of care and which physician interaction to evaluate. Consequently, we stopped collecting data pertaining to patient satisfaction. This change was made after 33 women had received the survey.

\section{Discussion}

Established social support networks and access to reliable information have been identified as important needs of women undergoing mammography (27-29). This pilot study is important because it extends the use of CHESS to the pre-diagnosis stage of breast cancer, in contrast to the conventional use of CHESS, which was directed towards women with newly diagnosed breast cancer navigating treatment decisions (39-43).

The results of this study show that Early CHESS decreased anxiety in women who experienced an abnormal screening mammogram at the time of biopsy, but not at diagnostic work-up. It is important to note that the second assessment was performed when the women presented for their diagnostic mammogram, prior to any interaction with the breast imaging team. However, the third assessment was performed just prior to biopsy (for those needing biopsy), after the women had interacted with members of the breast imaging team. These results may suggest that when combined with interactions with a care team, Early CHESS helps to decrease the anxiety associated with abnormal screening mammograms. This difference could also be explained by increased motivation of the study participants who have been recommended for biopsy to use Early CHESS. 
A potential reason for the absence of a significant difference in the breast cancer worry between both groups is that the LBCWS assesses long-term worry, rather than immediate anxiety like the SA, which would be harder to impact during the short duration of this study. Another possible limitation of this study is the large percentage of the study participants who had previously had an abnormal mammogram and/or breast biopsy (Figure 3), as this may have reduced the impact of Early CHESS on these women. Additionally, only a small number of women went on to biopsy, which could have limited our ability to detect the impact of Early CHESS on the study participants who went on to have a biopsy.

Potential directions for future research include evaluation of how much time women need to spend using the Early CHESS system in order to experience a significant decrease in anxiety, and which components of the Early CHESS system have the most impact on patient anxiety.

We did not include patient satisfaction in our analysis, because we found that many of the participants could not answer the questions assessing satisfaction with their physician interaction. This was mainly because these women did not know who their physician was for this process of care and which physician interaction to evaluate, and is likely due to the fact that they did not have a physician taking responsibility for this interaction. This discovery indicates a problem in the system of care and may underscore an opportunity to clarify roles, responsibility, and ownership of patient interactions, particularly in multidisciplinary care settings.

These results have clinical implications for the field of breast imaging, where anxiety in women undergoing screening mammography has increasingly been recognized as an important issue. In 2009, the US Preventive Services Task Force revised their recommendation for breast cancer screening with mammography in women between the ages of 40 and 49, based in large part on the perceived harms (including anxiety) related to false positive mammograms (2). The willingness to forego the mortality reductions of mammography in order to avoid such harms underscores the importance of better quanitifying, understanding and reducing anxiety related to breast cancer screening. Therefore, using tools such as Early CHESS to help reduce anxiety may be useful.

In conclusion, Early CHESS may decrease anxiety in women who experience abnormal screening mammograms, when combined with interactions with the breast imaging team. Early CHESS was designed to empower women to seek more information regarding abnormal mammograms and to get their questions answered, but the results of this study indicate that earlier in the work-up process, when there is not an identifiable care team (as indicated by inability to complete patient satisfaction surveys), providing a resource like Early CHESS may not help to reduce anxiety. However, after interacting with a healthcare provider, once women have an identifiable care team, they are better able to employ the coping mechanisms and information that Early CHESS provides to potentially reduce anxiety. This indicates that the combination of both Early CHESS and the interaction between the patient and her clinician is important in helping to reduce anxiety. 


\section{Acknowledgments}

We thank Mary Blum, RN, CBCN, Shawn Klasek, RN, BSN, CBCN, and Terri White, RN, MSN, CBCN, for their help with patient recruitment and communication. We also thank Kristi Klein, BA, RTR (M), for input on study design and implementation.

Funding source statement

This work was funded by the National Institute of Health (grant number R01CA165229, R01LM010921, and P50CA137216). The study sponsors had no role in the study design, data collection, analysis and interpretation, or the manuscript writing and preparation process.

\section{Appendix 1}

LIST OF 5 WEBSITES GIVEN TO THE COMPARISON GROUP: These five websites were selected because they were the five most highly used weblinks in the CHESS module and they represented some of the most widely known and trusted websites for providing content related to breast cancer and breast cancer screening. The 5 websites are:

American Cancer Society

http://www.cancer.org/healthy/findcancerearly/examandtestdescriptions/index

BreastCancer.org

http://www.breastcancer.org/symptoms/testing/

Imaginis

http://www.imaginis.com/breast-health/breast-health-non-cancerous-breast-issues

National Cancer Institute

http://www.cancer.gov/cancertopics/factsheet/Detection/mammograms

Susan G Komen for the Cure

http://ww5.komen.org/breastcancer/earlydetectionampscreening.html

\section{Appendix 2}

For each patient, the change score for STAI at the time of diagnostic work-up (STAI.Dx) was calculated by subtracting the STAI score at baseline from the score at the time of diagnostic work-up (i.e. STAI.PreDx = STAI.Dx - STAI.Pre). The percent change in STAI at diagnostic work-up was then calculated by taking the ratio of the change score to the baseline score, and multiplying by 100 (i.e. STAI.pctPreDx $=100 \times$ [STAI.Dx - STAI.Pre]/ STAI.Pre). The percent change in STAI at the time of biopsy was similarly calculated by taking the ratio of the change score for STAI at biopsy to the baseline score, and multiplying by 100 (i.e. STAI.pctPreBx $=100 \times$ [STAI.Bx - STAI.Pre]/STAI.Pre). Percent change scores for the LBCWS measure at diagnostic work-up and at the time of biopsy were similarly calculated. Summary measures (mean, median, standard deviation and extremes) were then obtained and depicted via box and whisker plots for each change score. 


\section{Bibliography}

1. Tabár L, Vitak B, Chen TH, Yen AM, Cohen A, Tot T, Chiu SY, Chen SL, Fann JC, Rosell J, Fohlin H, Smith RA, Duffy SW. Swedish two-county trial: impact of mammographic screening on breast cancer mortality during 3 decades. Radiology. 2011; 260(3):658-663. [PubMed: 21712474]

2. Kerlikowske K, Grady D, Barclay J, Sickles EA, Eaton A, Ernster V. Positive predictive value of screening mammography by age and family history of breast cancer. J Am Med Assoc. 1993; 270(20):2444-2450.

3. US Preventive Services Task Force. Screening for breast cancer: U.S. Preventive Services Task Force recommendation statement. Ann Intern Med. 2009; 151(10):716-726. W-236. [PubMed: 19920272]

4. Brett J, Bankhead C, Henderson B, Watson E, Austoker J. The psychological impact of mammographic screening. A systematic review. Psychooncology. 2005; 14(11):917-938. [PubMed: 15786514]

5. Brewer NT, Salz T, Lillie SE. Systematic review: the long-term effects of false-positive mammograms. Ann Intern Med. 2007; 146(7):502-510. [PubMed: 17404352]

6. Tyndel S, Austoker J, Henderson BJ, et al. What is the psychological impact of mammographic screening on younger women with a family history of breast cancer? Findings from a prospective cohort study by the PIMMS Management Group. J Clin Oncol. 2007; 25(25):3823-3830. [PubMed: 17761970]

7. Gram IT, Lund E, Slenker SE. Quality of life following a false positive mammogram. Br J Cancer. 1990; 62(6):1018-1022. [PubMed: 2257206]

8. Sutton S, Saidi G, Bickler G, Hunter J. Does routine screening for breast cancer raise anxiety? Results from a three wave prospective study in England. J Epidemiol Community Health. 1995; 49(4):413-418. [PubMed: 7650466]

9. Gram IT, Slenker SE. Cancer anxiety and attitudes toward mammography among screening attenders, nonattenders, and women never invited. Am J Public Health. 1992; 82(2):249-251. [PubMed: 1739156]

10. Jatoi I, Zhu K, Shah M, Lawrence W. Psychological distress in U.S. women who have experienced false-positive mammograms. Breast Cancer Res Treat. 2006; 100(2):191-200. [PubMed: 16773439]

11. Chen CC, David A, Thompson K, Smith C, Lea S, Fahy T. Coping strategies and psychiatric morbidity in women attending breast assessment clinics. J Psychosom Res. 1996; 40(3):265-270. [PubMed: 8861122]

12. Lampic C, Thurfjell E, Bergh J, Sjoden PO. Short- and long-term anxiety and depression in women recalled after breast cancer screening. Eur J Cancer. 2001; 37(4):463-469. [PubMed: 11267855]

13. Lowe JB, Balanda KP, Del Mar C, Hawes E. Psychologic distress in women with abnormal findings in mass mammography screening. Cancer. 1999; 85(5):1114-1118. [PubMed: 10091796]

14. Sandin B, Chorot P, Valiente RM, Lostao L, Santed MA. Adverse psychological effects in women attending a second-stage breast cancer screening. J Psychosom Res. 2002; 52(5):303-309. [PubMed: 12023127]

15. Scaf-Klomp W, van Sonderen FL, Stewart R, van Dijck JA, van den Heuvel WJ. Compliance after 17 years of breast cancer screening. J Med Screen. 1995; 2(4):195-199. [PubMed: 8719148]

16. Brett J, Austoker J. Women who are recalled for further investigation for breast screening: psychological consequences 3 years after recall and factors affecting re-attendance. J Public Health Med. 2001; 23(4):292-300. [PubMed: 11873891]

17. Lindfors KK, O'Connor J, Parker RA. False-positive screening mammograms: effect of immediate versus later work-up on patient stress. Radiology. 2001; 218(1):247-253. [PubMed: 11152810]

18. Brodersen J, Siersma VD. Long-term psychosocial consequences of false-positive screening mammography. Ann Fam Med. 2013; 11(2):106-115. [PubMed: 23508596]

19. Ekeberg O, Skjauff H, Karesen R. Screening for breast cancer is associated with a low degree of psychological distress. Breast. 2001; 10(1):20-24. [PubMed: 14965553] 
20. Meystre-Agustoni G, Paccaud F, Jeannin A, Dubois-Arber F. Anxiety in a cohort of Swiss women participating in a mammographic screening programme. J Med Screen. 2001; 8(4):213-219. [PubMed: 11743038]

21. Cockburn J, Staples M, Hurley SF, De Luise T. Psychological consequences of screening mammography. J Med Screen. 1994; 1(1):7-12. [PubMed: 8790480]

22. Olsson P, Armelius K, Nordahl G, Lenner P, Westman G. Women with false positive screening mammograms: how do they cope? J Med Screen. 1999; 6(2):89-93. [PubMed: 10444727]

23. Aro AR, Pilvikki Absetz S, van Elderen TM, van der Ploeg E, van der Kamp LJ. False-positive findings in mammography screening induces short-term distress - breast cancer-specific concern prevails longer. Eur J Cancer. 2000; 36(9):1089-1097. [PubMed: 10854941]

24. Pineault P. Breast Cancer Screening: Women's Experiences of Waiting for Further Testing. Oncol Nurs Forum. 2007; 34(4):847-853. [PubMed: 17723985]

25. Lebel S, Jakubovits G, Rosberger Z, et al. Waiting for a breast biopsy. Psychosocial consequences and coping strategies. J Psychosom Res. 2003; 55(5):437-443. [PubMed: 14581098]

26. Deane KA, Degner LF. Information needs, uncertainty, and anxiety in women who had a breast biopsy with benign outcome. Cancer Nurs. 1998; 21(2):117-126. [PubMed: 9556938]

27. Shaw CR, Wilson SA, O'Brien ME. Information needs prior to breast biopsy. Clin Nurs Res. 1994; 3(2):119-131. [PubMed: 8173518]

28. Ong G, Austoker J. Recalling women for further investigation of breast screening: women's experiences at the clinic and afterwards. J Public Health Med. 1997; 19(1):29-36. [PubMed: 9138214]

29. Barton MB, Morley DS, Moore S, et al. Decreasing women's anxieties after abnormal mammograms: a comparisonled trial. J Natl Cancer Inst. 2004; 96(7):529-538. [PubMed: 15069115]

30. McMullan M. Patients using the Internet to obtain health information: how this affects the patienthealth professional relationship. Patient Educ Couns. 2006 Oct; 63(1-2):24-28. [PubMed: 16406474]

31. Ekman A, Hall P, Litton JE. Can we trust cancer information on the Internet?--A comparison of interactive cancer risk sites. Cancer Causes Comparison. 2005; 16(6):765-772.

32. Hesse BW, Nelson DE, Kreps GL, et al. Trust and sources of health information: the impact of the Internet and its implications for health care providers: findings from the first Health Information National Trends Survey. Arch Intern Med. 2005; 165(22):2618-2624. [PubMed: 16344419]

33. McTavish FM, Gustafson DH, Owens BH, et al. CHESS: An interactive computer system for women with breast cancer piloted with an under-served population. Proc Annu Symp Comput Appl Med Care. 1994:599-603. [PubMed: 7949998]

34. Spielberger, CGR.; Lushene, R. State-Trait Anxiety Inventory Manual (STAI). Palo Alto, CA: Consulting Psychologists; 1970.

35. Lerman C, Trock B, Rimer BK, Jepson C, Brody D, Boyce A. Psychological side effects of breast cancer screening. Health Psychol. 1991; 10(4):259-267. [PubMed: 1915212]

36. Gustafson DH, Hawkins R, Pingree S, McTavish F, Arora NK, Mendenhall J, Cella DF, Serlin RC, Apantaku FM, Stewart J, Salner A. Effect of computer support on younger women with breast cancer. Journal of General Internal Medicine. 2001; 16(7):435-445. [PubMed: 11520380]

37. Loblaw DA, Bezjak A, Singh PM, et al. Psychometric refinement of an outpatient, visit-specific satisfaction with doctor questionnaire. Psychooncology. 2004 Apr; 13(4):223-234. [PubMed: 15054727]

38. R Development Core Team. R: A language and environment for statistical computing. Vienna, Austria: R Foundation for Statistical Computing; 2009. ISBN 3-900051-07-0. http://www.Rproject.org.

39. Gustafson DH, McTavish FM, Stengle W, et al. Use and Impact of eHealth System by Lowincome Women With Breast Cancer. Journal of health communication. 2005; 10(Suppl 1):195218. [PubMed: 16377608]

40. Baker TB, Hawkins R, Pingree S, et al. Optimizing eHealth breast cancer interventions: which types of eHealth services are effective? Translational behavioral medicine. 2011; 1:134-145. [PubMed: 21709810] 
41. Kim E, Han JY, Moon TJ, et al. The process and effect of supportive message expression and reception in online breast cancer support groups. Psychooncology. 2012; 21:531-540. [PubMed: 21416553]

42. Rahm AK, Dearing J, Barela B, et al. PS2-30: Implementing CHESS eHealth Breast Cancer Support in Population-Based Care. Clin Med Res. 2013 Sep; 11(3):160-161.

43. Hawkins RP, Pingree S, Baker T, et al. Integrating eHealth With Human Services for Breast Cancer Patients. Transl Behav Med. 2011 Mar; 1(1):146-154. [PubMed: 22496712] 


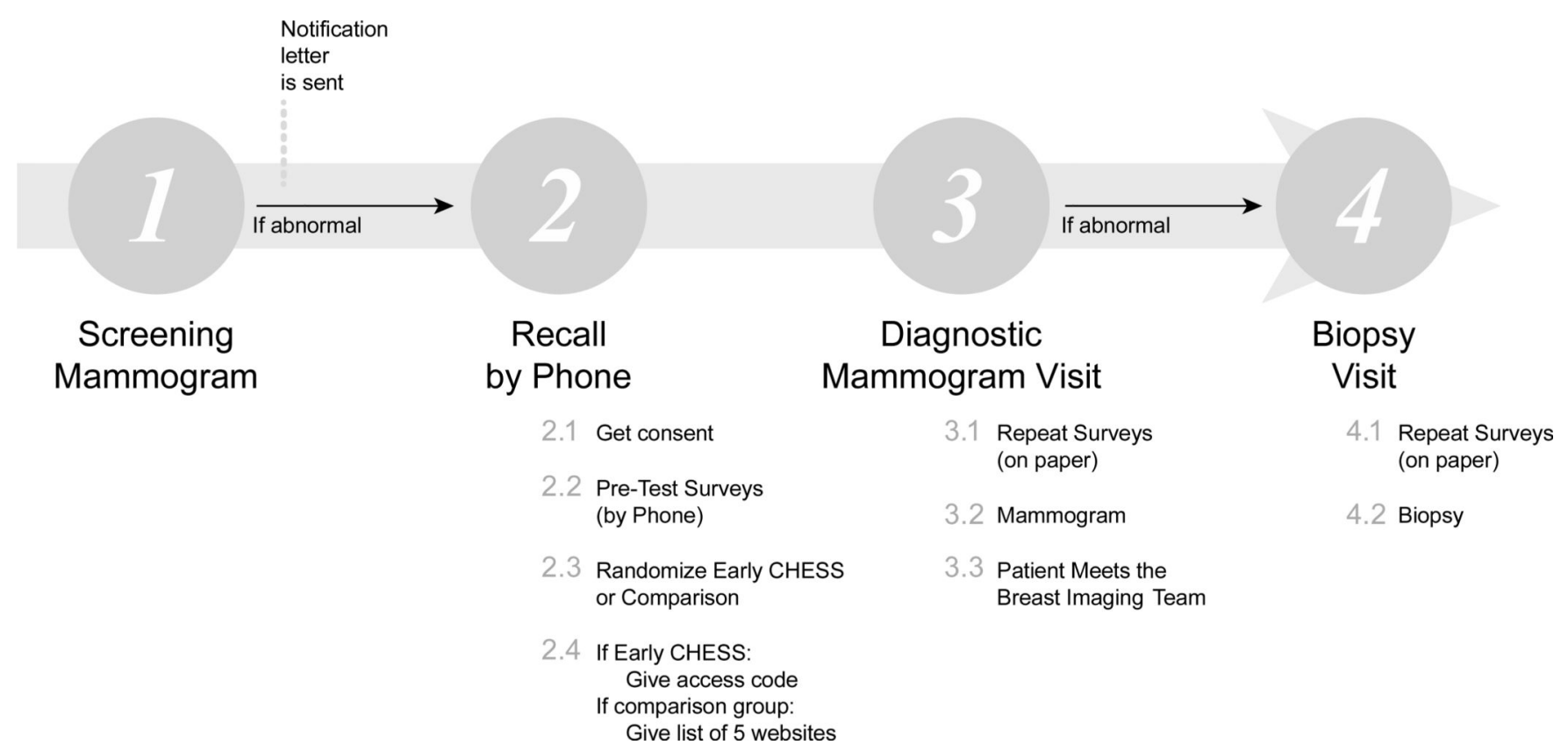

Figure 1.

Timeline and assessments 


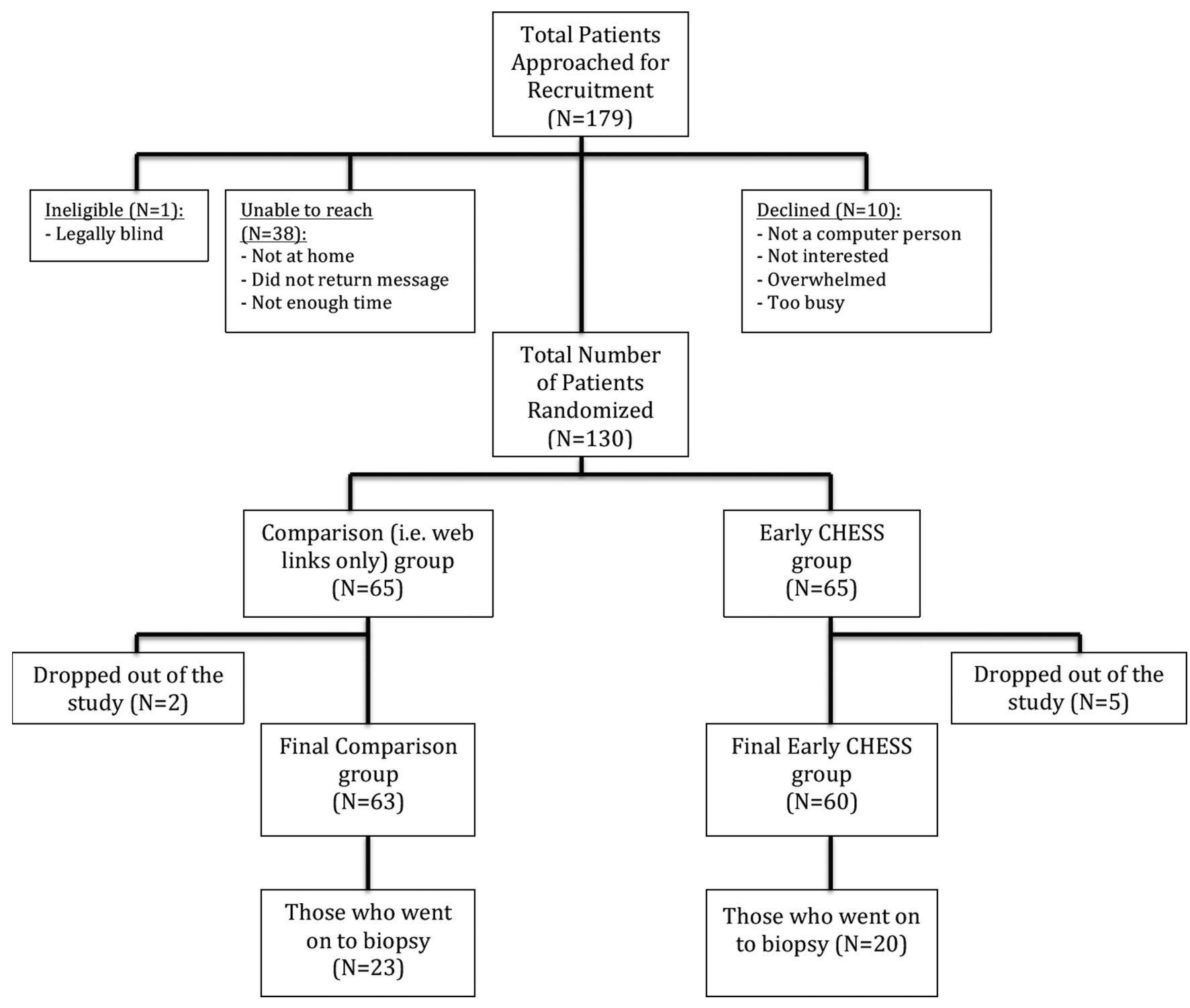

Figure 2.

Consort diagram 


\section{Breast History by Randomization Group}

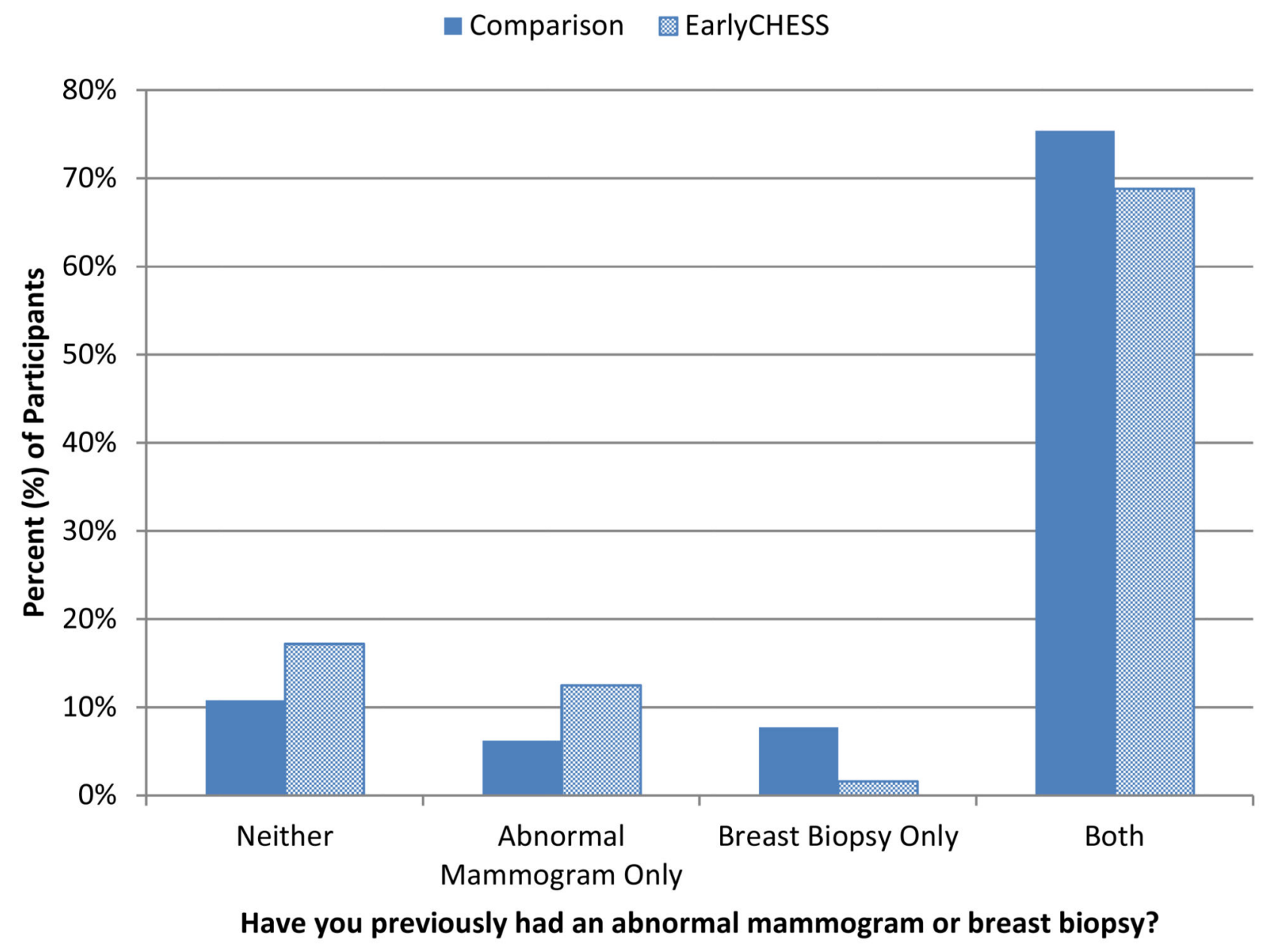

Figure 3.

Patient history of prior abnormal mammogram and/or breast biopsy for the Comparison and Early CHESS groups 
STAI $(P=0.24)$

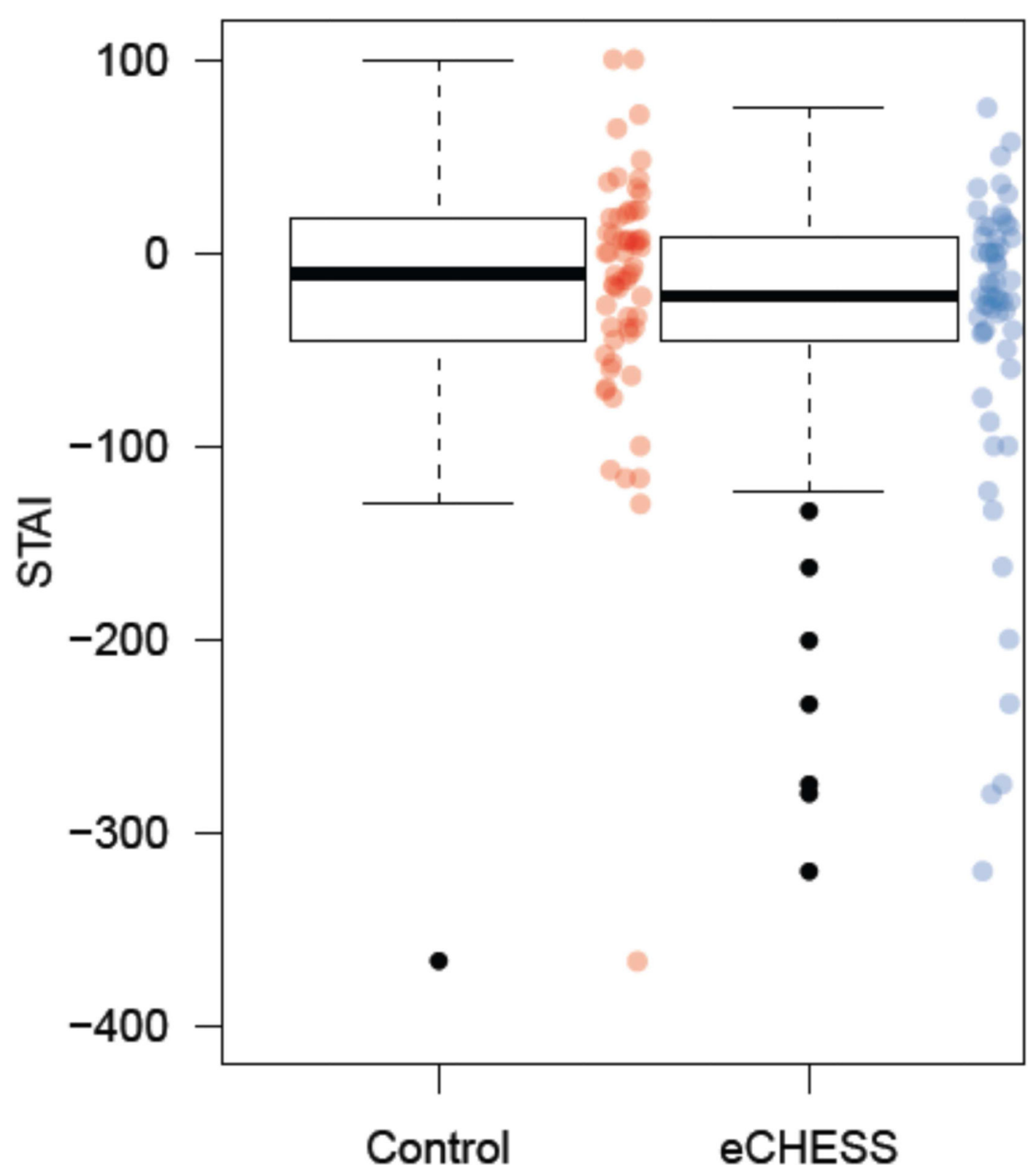

Figure 4.

Impact of Early CHESS on women' anxiety at the time of diagnostic work-up 
STAI $(P=0.0165)$

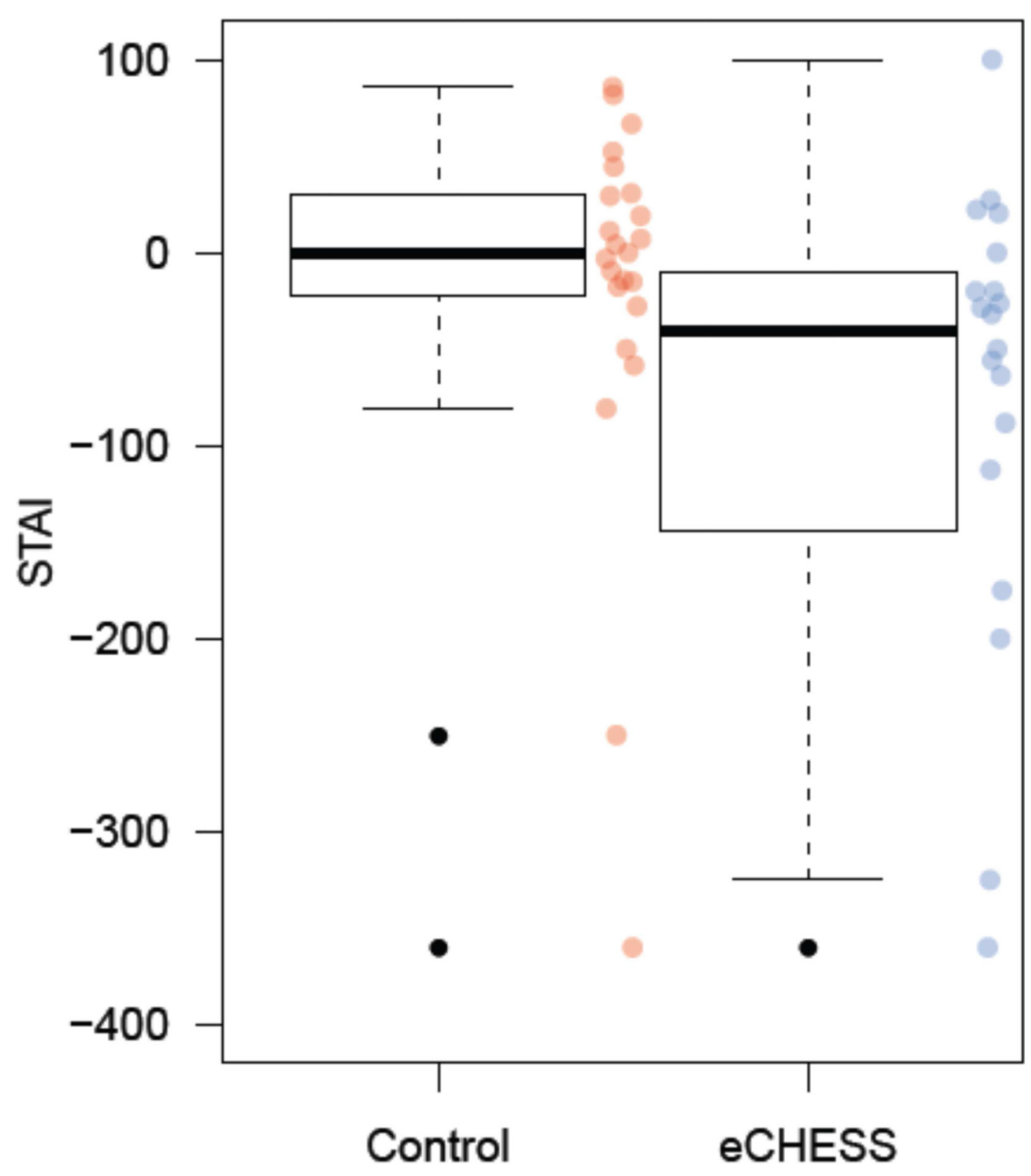

Figure 5.

Impact of Early CHESS on women' anxiety at the time of biopsy 